\title{
Analysis on the Policies of FDI from SMEs about Chinese Out-going Strategy
}

\author{
Qianfeng Wang ${ }^{1}$ \\ ${ }^{1}$ School of Social Sciences, Shanghai University of Engineering Science, Shanghai, China \\ Correspondence: Qianfeng Wang, Deputy Director of the Department of Business Administration, School of \\ Management, Shanghai University of Engineering Science, Shanghai, China. E-mail: wqf_sdu@163.com
}

Received: October 4, 2014

Accepted: November 5, 2014

Online Published: November 16, 2014

doi:10.5430/ijba.v5n6p61

URL: http://dx.doi.org/10.5430/ijba.v5n6p61

\begin{abstract}
In recent years, Chinese government is committed to the development of the small and middle-sized enterprises' (SMEs') out-going strategy and actively encourages the local SMEs participate in the foreign management and competition in various forms. But the current status quo of the foreign direct investment (FDI) from SMEs isn't optimistic which exists many serious problems. The paper will firstly analyze the situations of the FDI from SMEs in China trying to find out the defects and problems. Secondly in view of the existing problems and shortcomings, the paper will put forward the strategy choices and policy supports of developing the FDI from SMEs in China from the SMEs itself and government levels respectively hoping to be able to help Chinese SMEs promote effectively the FDI.

Keywords: out-going strategy, small and middle-sized enterprise, foreign direct investment, policy support

1. Introduction

The rapid increase of FDI by SMEs has been an obvious phenomenon. China's SMEs also go outside and invest in foreign countries. It is a statistic by China's ministry of commerce; the latest data shows domestic investors did FDI in 5090 foreign enterprises in 154 countries and regions in 2003, adding up to $\$ 90.17$ billion of financial unrelated investment. There are more than 20000 China's enterprises did foreign investment, $70 \%$ of those are SMEs. FDI policies of SMEs become the major part of transnational management of China's enterprises, whose failure has determined the accomplishment of Chinese Out-going strategy.
\end{abstract}

Analysis of the status quo of FDI by SME

\section{Analysis of the Investment Scale and Benefits}

The investment scale of China's SMEs in foreign countries is relatively small, and the benefits are quite general. Taking Zhejiang province as an example for its large share of SME, the scale of overseas investment projects in there are of $\$ 1.91$ million on average, which is much lower than it of subsidiaries of transnational enterprises in developed countries, or $\$ 6$ million. In addition, according to incomplete statistics, the number of China's overseas benefits only accounts for about forty percent, while the loss of households account for about sixty percent, which means overall benefit of overseas investment is relatively bad.

\subsection{Analysis of the Investment Mode}

The number of enterprises invest overseas in trade way is high, and then followed by industrial projects. The general trend is that the coverage of business industries is gradually widened. At present, the field of China's overseas investment involved has been expanded gradually from trade and catering to fisheries, energy, textile and apparel, commercial retail etc. As for the investment approaches, most enterprises adopt green-field sole proprietorship or joint venture. Regarding to merger and acquisition widely used in international direct investment currently, several large-sized Chinese enterprises are trying to adopt this method, and however, only few SMEs get involved.

\subsection{Analysis of the Investment Industrial Structure}

In terms of industrial structure, foreign investments lay emphasis on primary products and industry, but ignore the investment in high technology industries; lay emphasis on consuming products investment, but ignore the productive investment; lay emphasis on investing the industries with weak domestic effect, but ignore investing the industries 
with strong and positive domestic effect. Amid the invested enterprises, foreign trade enterprises engaged in commodity circulation far more than productive-oriented enterprises. Unreasonable investment structure leads to the interrupted and segmentation of investment and domestic production enterprises so that it may increase foreign investment risks. In addition, in terms of the choice of investment currency, the share of USD is too large and single, which increase the foreign exchange risks of China's investment when the current international financial market full of changes.

\subsection{Analysis of the Investment Location}

Foreign enterprises mainly distribute in several developed countries, Southeast Asian countries and regions that around Russia and Eastern Europe, which of those trade-oriented overseas investment institutions focus on developed countries, such as the US, Europe and Japan. Manufacture-oriented overseas investment institutions focus on neighboring countries, like Southeast Asia. R\&D-oriented overseas investment institutions focus on a few developed countries, such as the US, Japan, etc.

From all analysis above, the status quo of FDI by SMEs is not very optimistic. Driving FDI by SMEs and gaining efficient rewards need the common efforts from both enterprises themselves and the government.

\section{The Government Strategic Support of Active Developing FDI by SMEs}

The development of China's FDI by SMEs also depends on a series of policy support of the government. Diamond model proposed by Porter in 1990 provided some theoretical basis to analysis the role of government in promoting FDI by SMEs. Two Canadian scholar, Tim Padmore \& Hervey Gibson, improved Michael porter's "diamond model", and then they proposed a GEM model to analysis enterprise group's competitiveness. Although this model aims at analyzing enterprise groups, but still does better in analyzing government's function in FDI by SMEs. The author thought that the government can play a role in the following aspects:

\subsection{Improve the Mechanism of Management of Foreign Investment}

Creating favorable system environment that is beneficial to FDI, and optimizing public policies in related laws and regulations, property rights, financial, fiscal, labor supply, the sustainable development etc.

\subsection{Cultivating a Variety of Specifications of Intermediary Service Agencies}

Provide several service related to FDI by SMEs such as offering real and usefui information, technical consulting, entrepreneurship, finance service, personnel training etc. Many failure of FDI by SMEs lies in poor understanding the laws and regulations policy for the host country. The government can set up a batch of intermediary agencies via policy supporting, in order to help SMEs collect information about overseas markets, which can largely reduce the risks of FDI.

\subsection{Cultivating Transnational Operation Talents}

SMEs just lack those professional talents, which seriously hinder the development of FDI, and increase the investment risks. With fastening pace of FDI by SMEs, transnational management talents become increasingly important and demanding. They must not only proficient in business management, economy, technology and other aspects of professional knowledge and skills, but also need to understand a foreign language and international traditions, get familiar with the country's foreign economic policy and regulations, and master the laws of the host country, local cultural customs. Local governments can make full use of the advantage of local colleges and universities, subject, actively cultivating the multidisciplinary cross foreign talents, it not only can smoothly promote FDI by SMEs, but also improve the ability of SMEs to accomplish multinational business, good for enhancing the international competitiveness of enterprises and the degree of internationalization.

FDI by SMEs is one of the methods for Chinese Out-going strategy. Unlike domestic investment, FDI isn't just a simple extension of the domestic business activities, but the optimization and expand of business organizations and management elements, because its investment benefit and risks will put in international market directly. Therefore, the key factors in the success of FDI by SMEs depend on their strategy choice.

\section{The Strategy Choice of Active Developing FDI by SMEs}

\subsection{SMEs Should Fully Understand Their Pros and Cons, and Then Choose Reasonable Investment Location}

Overseas markets where we invest can be divided into Southeast Asia, Latin America, Russia and Eastern Europe, Africa as well as Europe and America. In general, the difficulties for SMEs to invest in Europe and America is quite bigger, so our first choice can be a developing countries for cheap production cost, and later enter the market channels in developed countries, such as Europe and the US. Thanks for geographical advantage in China and 
Southeast Asia; there are many Chinese settlements in plenty of countries, which provide favorable conditions for FDI. Moreover, current economic level and industry level in China is similar to what in the region, which is much more convenient to transfer domestic matured technology and industry, even have unparalleled advantages than other locations in culture, language etc.

In the process of FDI, investment failures caused by cultural conflict is also ordinary, therefore, investing in the region can reduce risks to a certain extent. The culture and geographic situation of Latin America is similar to those in Europe and the US, so investing in this region may easily get access into Europe and the US market. Many matured techniques and products of China's SMEs have some pros and markets in Russia and Eastern Europe have certain advantages and market. But the politics there is unstable and there are some hidden threatens in social orders. Thus, SME should be prepared for before their investment. Economy in Africa has an obvious improvement in recent years, since most of the regions there are less developed countries (LDC), investment here can enjoy many preferential terms from the developed countries. However, SMEs may suffer poor investment environment of Africa, incomplete policy and law, higher political risks. Despite the great difficulty in entering the European and the US markets, but recently, there are still some SMEs invest in the region successfully. The matured techniques and cheap products that China's SMEs own still has certain comparative advantage in these areas.

\subsection{SMEs Must Have a Reasonable Risk Management Awareness and Decision-making Mechanism}

There are huge differences for SMEs to invest in domestics or overseas, besides operating risks, they also have to face the exchange rate risks, political risks and risks of government regulation, etc. Hence, FDI by SMEs must do abundant of overseas market researches, follow the scientific investment decision-making procedures, and invest prudently. Before making decisions on transnational operation, it is necessary for SMEs to analysis the macro investment environment like political, social, economic, cultural, legal etc., and get to know the related policies and regulations of financial policy, foreign exchange control, company law, labor law, bankruptcy law etc. precaution averts perils.

According to different international political, economy, cultural environment and industry competition situation, SMEs make different ways of investment, what's more, they also need to compare the different countries and regions, then target those countries and projects with high safety degree and big profits.

\subsection{Utilizing the Advantages of the Host Country Fully}

So-called location advantage refers to the more beneficial operation conditions and relative advantages in different countries and regions than those in where the enterprises are. To avoid constraints like exchange rate controls, import and export barriers, SMEs can reduce the amount of imported techniques and resources, and make full use of geographical advantages to seek local raw materials and parts instead of imported.

SMEs can also fully utilize human resources of the host country so as to reduce the barriers caused by language, culture etc. to the market development. Some companies have noticed that, in terms of the cost, hiring locals than is much more economical than hiring domestic workers. Therefore, no matter management or cost saving, hiring local people is a reasonable choice of FDI by SME. Before the investment, thus, SMEs also need to be aware of the location related information.

However, due to constraints such as capital, poor ability of SMEs to get external market information leads them difficult to obtain accurate information about location advantages. SMEs can gain related information through the information support from government or agency, and the alien between each other or accessing to the Internet.

4.4 Establishing Strategic Alliance, Joining into a Global Network of International Division of Labor and Cooperation, and Giving Full Play to the Advantages of SME Group

Due to limited power FDI by SMEs is still quite rough for the most of time. Then, joining into the international industrial division of labor and collaboration network of multinational management has become a significant strategic choice for today's FDI by SME. Many China's SMEs has strong power in technology-intensive and labor-intensive or production management, so they join in international industrial division of labor and cooperation network with minimum cost for their core competitiveness in some field. With the help of industrial division of labor and cooperation network, SMEs can utilize various advantages of big enterprises to overcome their difficulties in credit ability, awareness, negotiating position etc. so that it may reduce the risks of market uncertainty.

Multinational strategic alliance is also the most important trend of the development of global economic integration, because it can be a strategic goal of long-term relationships, also can be to get the vested interests to form a short-term relationship; it can be either vertical cooperation between small businesses and large enterprises, it can 
also be is almost the same size of the horizontal joint between small and medium-sized enterprises.

In addition, SMEs also cannot ignore the advantage of enterprise group. Advantages brought by the SME's innovation greatly promote the international competitiveness of Chinese industry. Through collaboration relations and other forms of SME group and then outward invest together, which can enhance the anti-risk ability of FDI. SMEs of Italian development mode, such as mesh furniture enterprises group development model, "invisible large factory" model, unaffected Putnam's model etc. can provide reference for FDI by SMEs in China.

At present, China's SMEs go out by themselves and they are not strong enough and failed to play the advantages effectively. In order to improve the success probability of FDI, FDI by SMEs need to overcome the traditional idea of region segmentation, competing for interests and the individual ideas, instead of changing the traditional concept of competition, setting the new idea of cooperative competition, therefore, establishing strategic alliance, joining the division of labor and cooperation network, forming the enterprise group, all of them are an effective selections.

\section{Conclusion}

FDI will become an important path for the sustainable development of Chinese SMEs in the future and also the key part of Chinese economic development. In order to better develop Chinese SMEs' FDI, the SMEs need diversified investment modes improving the industrial structure and investment location choices and at the same time they also need the governmental necessary supports at the macro level making great efforts to cultivate the related professional talents and optimizing the public policies and professional services of the FDI.

\section{References}

Feng, Delian, \& Xu Jiexiang. (2004). Research on SMEs Cluster and the International Competitiveness of Chinese Industry. Northern Economy and Trade, (5).

Ji, Xiaowei. (2012). Study on the FDI of SMEs "Market Leader" Model. Commercial Times, (3).

Peng, Zhiyong. (2013). Analysis on the FDI Strategy of Chinese Enterprises. Enterprises Economy, (2).

Shangguan, Xuejin, \& Hu, Fengling. (2003). Study on the Feasibility of Chinese SMEs' FDI. Journal of International Trade, (8).

Yang, Jianmei, \& Yang, Jing. (2003). Evaluation on GEM Model of Enterprises Cluster Competitiveness and its' Application. Science of Science and Management of $S \& T,(2)$. 